\section{Conservation: in a rut, we need rut-inspired solutions}

SIR - Your Editorial 'The great divide' (Nature 450, 135-136; 2007) pointed to a persistent and problematic issue plaguing conservation: the gap between research and practice. You suggest that conservation biologists should spend more time working with local practitioners and get out of their ruts.

It's true that conservation biology is in a rut. So we need rut-inspired solutions.

The ruts are the cultures and institutions that impede engagement by conservation scientists. A descendant of population biology, conservation science inherited cultures and institutions that may have been suitable for other sciences but are not suitable for conservation science. We are blocked on several fronts.

First, conservation science traditionally focused narrowly on biology, largely omitting the social sciences and humanities. Because conservation is fundamentally the management of human behaviour, this omission has impeded effective application of research. Thankfully, efforts are under way to broaden and integrate conservation research.

Second, engaging society in conservation science is still controversial. And until we sort out what constitutes appropriate engagement, it will rightly remain so.

Third, engagement is generally not valued highly as a professional activity.

The Society for Conservation Biology should publicly declare that engagement is a crucial responsibility of academic conservation scientists. Candidates and reviewers for promotion and tenure could cite this to justify their choices. Such a statement could have intangible and knockon effects for other scientists too.

To promote effective engagement - and escape this rut - we conservation scientists must first engage our own cultures and institutions.

Kai M. A. Chan

Institute for Resources, Environment and Sustainability, AERL Rm 438, 2202 Main Mall, University of British Columbia, Vancouver, British Columbia V6T 1Z4, Canada

\section{Conservation: academics should 'conserve or perish'}

SIR - Your Editorial 'The great divide' (Nature 450, 135-136; 2007) underlines the immense gap between academia and practice in conservation biology. This is simply an evolutionary consequence of selective forces at play for academics.

Turning one's research findings into actions is good for conservation but not necessarily for an academic career. It reduces the time available for preparing manuscripts - and academics in conservation biology are evaluated on their publications, rather than on their involvement in saving species from extinction.

We suggest that an 'impact factor' should be created, inspired by the conventional metric of scientific publications, to assess tenureship applications for academic positions in the field.

This impact factor would be based on an estimation of how much worse the conservation status of an endangered species or ecosystem might be in the absence of the candidate's research. It would select for targeted investigation that should help to fill in 'the great divide', and would exclude opportunistic ecology papers claiming to be of conservation significance.

Such a dual evaluation process would not mean that all conservation academics should become green activists. The role of academics in society is, and should remain, to understand and explain the complexity of the world. It includes supporting evidence-based policy-making in biodiversity conservation. Guillaume Chapron ${ }^{\star}$, Raphaël Arlettaz $†$

${ }^{\star}$ Grimsö Wildlife Research Station,

Swedish University of Agricultural Sciences, 73091 Riddarhyttan, Sweden

†Conservation Biology Division, Institute of

Zoology, University of Bern, Baltzerstrasse 6, 3012 Bern, Switzerland

\section{Frog transparency led to discovery of melatonin}

SIR - Your News in Brief story 'See-through frog offers inside information' (Nature 449, $521 ; 2007)$ describes the production of a transparent frog by genetic manipulation. But translucent amphibians were first artificially created 90 years ago.

C. P. McCord and F. P. Allen (J. Exp. Zool. $23,207-224$; 1917) reported that a crude acetone extract of bovine pineal glands fed to Rana pipiens tadpoles caused such a pronounced lightening of their skins that the larger viscera were visible through the dorsal body wall. The tadpoles' transparency varied according to the concentration of pineal extract in the water in which they were swimming.

Some 40 years later, the dermatologist A. B. Lerner followed up these observations and discovered that a pineal indole caused the melanin granules in frog melanocytes to aggregate and the skin to lighten - he named this factor melatonin (A. B. Lerner et al.

J. Am. Chem. Soc. 80, 2587; 1958).

So the suggestion made by S. CastroviejoFisher and colleagues in Correspondence, of using naturally transparent arboreal glass frogs of the family Centrolenidae for biomedical research, is not without precedent ('Transparent frogs show potential of natural world' Nature 449, 972; 2007).

Thomas C. Erren ${ }^{\star}$, Russel J. Reiter $\uparrow$,

V. Benno Meyer-Rochow:

*Institute and Policlinic for Occupational and Social Medicine, University of Cologne, Kerpenerstrasse 62, 50937 Köln, Lindenthal, Germany †Department of Cellular and Structural Biology, University of Texas Health Science Center at San Antonio, San Antonio, Texas 78229-3900, USA $¥$ School of Engineering and Science, Jacobs University Bremen, 28759 Bremen, Germany

\section{Schizophrenia is a disease, so electrons aren't at risk}

SIR - In your News \& Views article 'Schizophrenic electrons' (Nature 450, 492-493; 2007), electrons are called 'schizophrenic' because they display split personalities. This inappropriate use of metaphor perpetuates a misunderstanding of a serious illness. Multiple personalities are not a feature of schizophrenia. Rather, schizophrenia is characterized by a combination of 'positive' and 'negative' symptoms. The positive symptoms include delusions, hallucinations and thought disorders, whereas the negative symptoms include social withdrawal, flattened affect and lack of motivation.

I am willing to concede that electrons may have personalities; even that some electrons have split personalities. But to claim that electrons are 'schizophrenic' would require evidence beyond that described in the article. Ronald Chase

Department of Biology, McGill University, Montreal, Quebec H3A 1B1, Canada

\section{Schizophrenia does not mean split personality}

SIR - I was astonished to see the terms 'schizophrenic' and 'split personality' being used interchangeably in a News \& Views article on high-temperature superconductivity (Nature 450, 492-493; 2007).

Although the usefulness of the concept of 'schizophrenia' in mental health is contested, the consensus is that it does not have anything to do with a 'split personality' (whatever that is). Why, then, is Nature perpetuating this inaccurate and potentially offensive usage of 'schizophrenic'?

Alex C. W. May

Northwest Institute for Bio-Health Informatics, ISBE, University of Manchester, Oxford Road, Manchester M13 9PT, UK

Contributions to this page may be sent to correspondence@nature.com. 